\title{
Unleashing the untold and misunderstood observations on vitamin $\mathbf{E}$
}

\author{
Ping Tou Gee
}

Received: 18 May 2010/Accepted: 7 July 2010/Published online: 20 July 2010

(C) Springer-Verlag 2010

\begin{abstract}
Paradoxically, meta-analysis of human randomized controlled trials revealed that natural but not synthetic $\alpha$-tocopherol supplementation significantly increases all-cause mortality at $95 \%$ confidence interval. The root cause was that natural $\alpha$-tocopherol supplementation significantly depressed bioavailability of other forms of vitamin $\mathrm{E}$ that have better chemo-prevention capability. Meta-analysis outcome demonstrated flaws in the understanding of vitamin E. Reinterpretation of reported data provides plausible explanations to several important observations. While $\alpha$-tocopherol is almost exclusively secreted in chylomicrons, enterocytes secrete tocotrienols in both chylomicrons and small high-density lipoproteins. Vitamin E secreted in chylomicrons is discriminately repacked by $\alpha$-tocopherol transfer protein into nascent very low-density lipoproteins in the liver. Circulating very lowdensity lipoproteins undergo delipidation to form intermediate-density lipoproteins and low-density lipoproteins. Uptake of vitamin $\mathrm{E}$ in intermediate-density lipoproteins and low-density lipoproteins takes place at various tissues via low-density lipoproteins receptor-mediated endocytosis. Small high-density lipoproteins can deliver tocotrienols upon maturation to peripheral tissues independent of $\alpha$-tocopherol transfer protein action, and uptake of vitamin E takes place at selective tissues by scavenger receptormediated direct vitamin E uptake. Dual absorption pathways for tocotrienols are consistent with human and animal studies. $\alpha$-Tocopherol depresses the bioavailability of $\alpha$-tocotrienol and has antagonistic effect on tocotrienols in chemo-prevention against degenerative diseases. Therefore,
\end{abstract}

P. T. Gee $(\bowtie)$

Palm Nutraceuticals Sdn. Bhd., Batu 7, Jalan Mawai,

81900 Kota Tinggi, Johor, Malaysia

e-mail: geept@palmnutraceuticals.com it is an undesirable component for chemo-prevention. Future research directions should be focused on tocotrienols, preferably free from $\alpha$-tocopherol, for optimum chemo-prevention and benefits to mankind.

Keywords $\alpha$-Tocopherol - Tocotrienols . Chemo-prevention · Absorption pathways · Bioavailability

\section{Nomenclature}

Vitamin E comprises two main homologous series, tocopherol $(\mathrm{T})$ and tocotrienol $\left(\mathrm{T}_{3}\right)$. Both $\mathrm{T}$ and $\mathrm{T}_{3}$ have the same chroman ring but differ in the side chain in their structures. A T has a saturated phytyl side chain, whereas a $\mathrm{T}_{3}$ has a geranylgeranyl side chain with three double bonds in the remaining acyclic isoprene units. There are four homologs each for $\mathrm{T}$ and $\mathrm{T}_{3}\left(\alpha-\mathrm{T}, \beta-\mathrm{T}, \gamma-\mathrm{T}, \delta\right.$-T and $\alpha-\mathrm{T}_{3}$, $\left.\beta-\mathrm{T}_{3}, \gamma-\mathrm{T}_{3}, \delta-\mathrm{T}_{3}\right)$. The four homologs differ in the substitution at carbons-5 and 7 of the chroman-6-ol (Fig. 1). Carbons- 5 and 7 of the $\alpha-\mathrm{T}$ or $\alpha-\mathrm{T}_{3}$ are substituted with a methyl group each, whereas that of $\delta$-T or $\delta$-T $\mathrm{T}_{3}$ are unsubstituted. Carbon- 5 of $\beta$-T or $\beta-\mathrm{T}_{3}$ is substituted with a methyl group, whereas carbon-7 of $\gamma-\mathrm{T}$ or $\gamma-\mathrm{T}_{3}$ is substituted with a methyl group. Each $\mathrm{T}$ has eight stereoisomers, whereas each $\mathrm{T}_{3}$ has two stereoisomers. Natural $\mathrm{T}$ has $R R R$-configuration, whereas natural $\mathrm{T}_{3}$ has $R$-configuration. Tocomonoenol $\left(\mathrm{T}_{1}\right)$ forms the third homologous series of vitamin E. To date, two $\alpha-\mathrm{T}_{1} \mathrm{~s}$ isomers [44, 93] and a $\delta$ - $\mathrm{T}_{1}[16]$ are found in nature.

Vitamin $\mathrm{E}$ is a generic name referring to a group of compounds exhibiting qualitatively the biological activity of $\alpha$-T [35]. Obviously, $\alpha$-T is a form of vitamin $\mathrm{E}$ and not synonymous to vitamin $\mathrm{E}$. The term vitamin $\mathrm{E}$ encountered in the literature is often technically a misnomer when the 
Fig. 1 Structures of tocopherols and tocotrienols
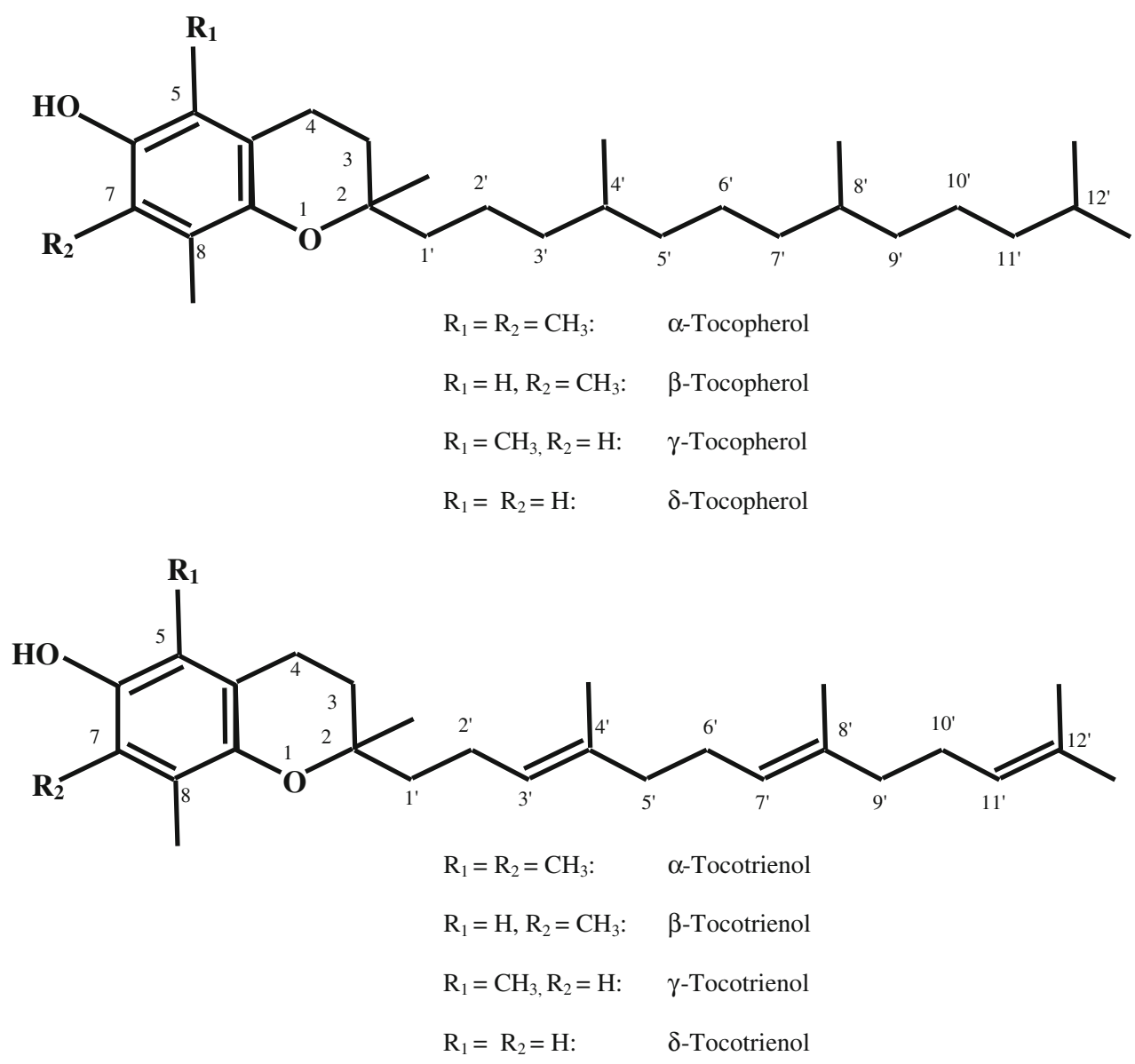

research involved $\alpha$-T or its esters only. Terms such as isomers, isoforms and vitamers were used to describe different forms of vitamin $\mathrm{E}$, and these inappropriate terms should be avoided. Many nutritionists, including those formulating the dietary reference intakes [34], adopted a different definition for vitamin E. They defined $2-R-\alpha-T \mathrm{~s}$ as vitamin $\mathrm{E}$, and other forms of vitamin $\mathrm{E}$, such as $\gamma$-T, $\delta$-T and $\mathrm{T}_{3}$, were ignored.

\section{Natural sources of vitamin $E$}

In contrast to ubiquitous $\mathrm{Ts}$, natural sources of $\mathrm{T}_{3} \mathrm{~s}$ are scarce. A recent expert opinion [70] indicates that most commercial vegetable oils are rich in Ts but do not contain significant amount of $\mathrm{T}_{3} \mathrm{~s}$ except palm oil and rice bran oil. Palm oil and rice bran oil are commercial sources of $\mathrm{T}_{3} \mathrm{~s}$. However, the vitamin $\mathrm{E}$ compositions of commercial $\mathrm{T}_{3}$ products are different from that given in the expert opinion, presumably due to poorer analytical techniques in the earlier days. Palm tocotrienol-rich fraction (TRF) is a mixture of $\mathrm{T}_{3} \mathrm{~s}, \alpha-\mathrm{T}$ and other natural components extracted from palm oil. In contrast to the data given in the review, palm TRF contains very little $(<0.5 \%)$ other Ts (non- $\alpha-\mathrm{T})$.
The ratios of $\alpha$-T to $T_{3}$ s in palm TRF (excluding that derived from palm fatty acid distillate) from five commercial sources are between $22: 78$ and 24:76. Greater variation is observed for rice bran TRF, the ratios of $\alpha$-T to $\mathrm{T}_{3} \mathrm{~s}$ from three commercial sources are 23:52, 30:53 and $43: 46$, respectively. Small quantity of $\mathrm{T}_{3} \mathrm{~s}\left(90 \% \quad \delta \mathrm{T}_{3}\right.$ and $10 \% \gamma-\mathrm{T}_{3}$ ) extracted from annatto beans are also commercially available.

Cereals contain tens of $\mathrm{mg}$ of $\mathrm{T}_{3} \mathrm{~s}$ per $\mathrm{kg}[59,67]$. Most fruits and vegetables in the United States diet do not contain $\mathrm{T}_{3} \mathrm{~s}$ except a few of them usually contain less than $1 \mathrm{mg}$ of $\mathrm{T}_{3} \mathrm{~s}$ per kg [11]. Scarcity of dietary $\mathrm{T}_{3} \mathrm{~s}$ and their poor absorption in human body suggest supplementation is needed, especially for non-palm oil or non-rice bran oil consumers.

\section{Background}

Two great hypotheses the free radical hypothesis of aging [24] and the oxidation hypothesis of atherosclerosis [8] aroused the interest on using antioxidant vitamins, including vitamin $\mathrm{E}$, for degenerative disease chemoprevention. 
Among all forms of vitamin $\mathrm{E}, \alpha-\mathrm{T}$ has the highest biological activity; it is the predominant form of vitamin $\mathrm{E}$ in the plasma irrespective of the contents of dietary intake and is also the only form of vitamin $E$ that human body maintains. Logically, it became the most focused research target as an antioxidant vitamin.

Randomized controlled clinical trial (RCT) is the highest level of evaluation of a compound for clinical applications. A single RCT has the limitation on population size and often the effect of the RCT may not be very obvious. Meta-analysis is a powerful statistical tool for pooling numerous RCTs with similar characteristics together and provides an overall outcome with higher confidence. However, it is inappropriate to include all the RCTs for meta-analysis, such as those involved confounding agents or different metabolisms in human body.

The hope on $\alpha$-T for prevention of various degenerative diseases was dashed when meta-analyses revealed that $\alpha$-T supplementation did not benefit mankind [3, 50].

The objectives of this review include reinterpreting selective published raw data on vitamin E, postulating hypotheses to provide plausible explanations and establishing future vitamin $\mathrm{E}$ research direction for the benefits of mankind.

\section{$\alpha$-T does more harm than good}

\section{Meta-analysis}

Up to October 2005, there were 55 RCTs that involved $\alpha$-T supplement and complied with the selection criteria [3]. Out of the 55 RCTs reported, 31 RCTs were co-supplemented. The remaining 24 RCTs involved 47,206 subjects on $\alpha$-T supplementation singly with reported mortality. $\alpha$-T supplementation showed non-statistically significant increased all-cause mortality, reported relative risk (RR) 1.02 , 95\% confidence interval $(95 \%$ CI) $0.98-1.05$. The meta-analysis further revealed that $\alpha$-T supplementation (excluding those involved $\beta$-carotene and selenium) in low-bias risk (good methodology quality) RCTs showed statistically significant increased all-cause mortality (RR $1.04,95 \%$ CI 1.01-1.07).

Re-analyzing the meta-analysis

Using the systematic review and meta-analysis reported [3], meta-analysis on RCTs is re-examined with specific focus on $\alpha$-T (and its esters) supplementation singly in order to obtain direct evidence, avoid heterogeneity and also avoid possible confounding effects among the supplements. The 24 RCTs are grouped into RCTs that were supplemented with natural $\alpha$-T (8 RCTs with 13,415 subjects) $[5,18,41,42,47,68,76,78]$, synthetic $\alpha$-T (10 RCTs with 32,988 subjects) [17, 20, 22, 27, 43, 48, 63, $69,86,87]$ and unspecified $\alpha-\mathrm{T}$ (6 RCTs with 803 subjects) [12, 13, 21, 45, 77, 91].

The mortality reported in 3 out of 24 RCTs [42, 47, 68] was combined data with other supplements. Separate mortality data for $\alpha$-T supplementation singly were available in two of the RCTs [42, 47], whereas that for the remaining RCT [68] was unavailable and was obtained from personal communication with the authors. After correcting the mortality data for $\alpha$-T supplementation singly in the 3 RCTs, meta-analysis was re-analyzed using fixed effects model instead of random effects model.

Paradoxical meta-analysis outcome

Figure 2 displays the intervention effect of natural and synthetic $\alpha$-T on all-cause mortality. Natural $\alpha$-T supplement significantly increases all-cause mortality, RR1.13 with 95\% CI 1.04-1.23. Exclusion of two small high-bias risk RCTs [18, 78] has little impact on the pooled effect (RR 1.12 with 95\% CI 1.03-1.22). Individually, none of the RCTs on natural $\alpha$-T supplement showed any beneficial effect. Six out of eight RCTs showed increased all-cause mortality, while the remaining two RCTs showed no effect for natural $\alpha$-T supplementation. Data for the six small RCTs [12, 13, 21, 45, 77, 91] on unspecified type of $\alpha$-T supplement were tested and found to have no impact on interpretation of pooled effects when all or selected RCTs were included into either natural or synthetic $\alpha$-T group for statistical analyses (results not shown here).

The effect of synthetic $\alpha$-T supplement was less obvious, showed non-statistically significant increased all-caused mortality for 5 low-bias risk RCTs (RR 1.03 95\% CI 0.99-1.07) but showed non-statistically significant decreased all-caused mortality for 5 high-bias risk RCTs (RR 0.95, 95\% CI 0.85-1.06). The opposite effects of synthetic $\alpha$-T supplementation in low-bias and high-bias risk RCTs had caused a compromised overall pooled effect (RR 0.99, 95\% CI 0.95-1.03).

For the first time, meta-analysis has demonstrated that a natural antioxidant vitamin is more harmful than its synthetic counterpart. This paradoxical observation also provided important evidence for identifying the root cause for unpredicted increase in all-cause mortality due to a nontoxic antioxidant vitamin supplement.

Interpretation of the meta-analysis

The marked negative effect observed for natural $\alpha$-T supplement but less obvious negative effect for synthetic $\alpha$-T supplement can be qualitatively explained by ligand specificity and relative binding affinities of natural and 
Fig. 2 Effect of natural and synthetic $\alpha$-T supplements on all-cause mortality

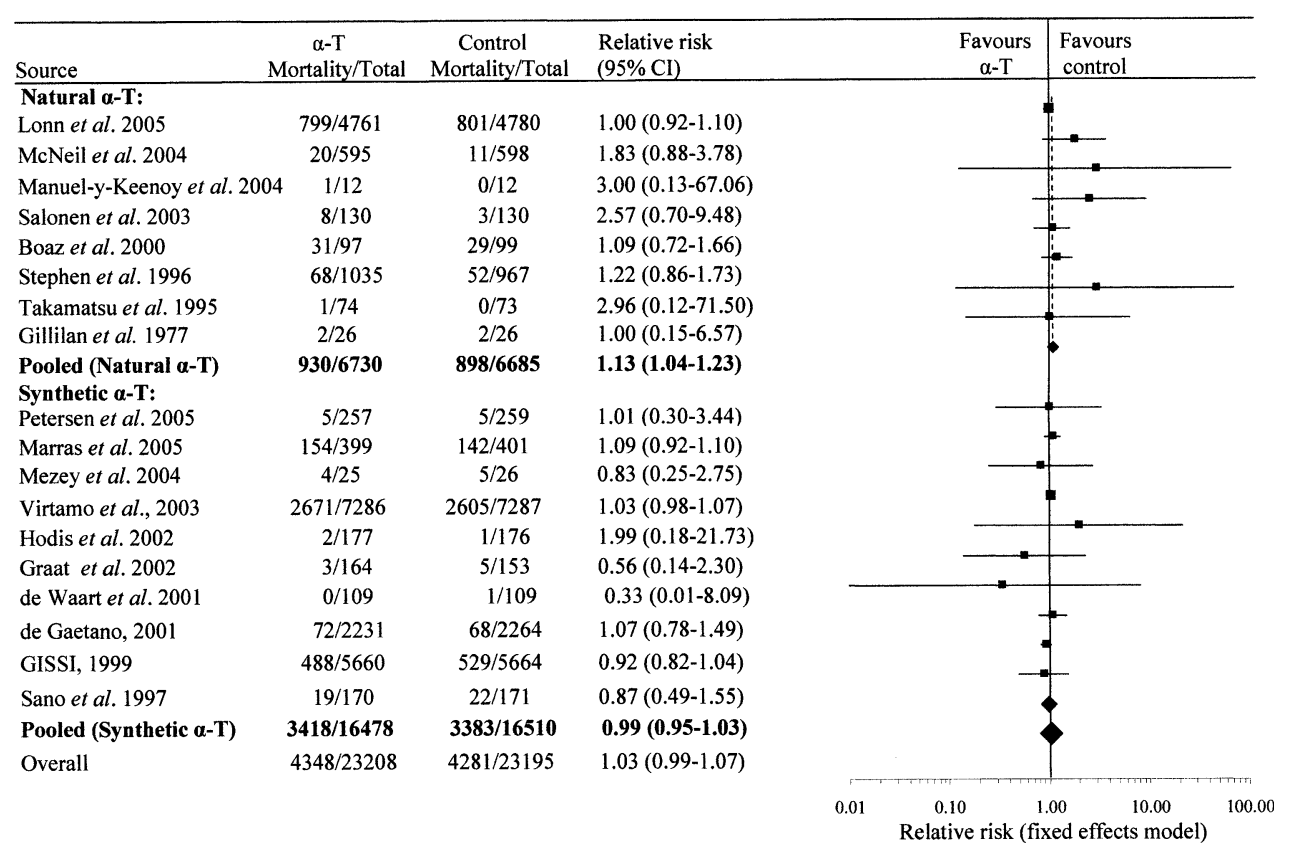

other forms of vitamin $\mathrm{E}$, based on the smaller difference in the relative binding affinity to $\alpha$-TTP.

The different binding affinity with $\alpha$-TTP suggested that natural and synthetic $\alpha$-Ts are metabolically different, and the outcome confirmed that it is inappropriate to combine natural and synthetic $\alpha$-Ts for meta-analysis. Surprisingly, the heterogeneity test in the random-effect model failed to reveal any difference $\left(I^{2}=0\right)$ between natural and synthetic $\alpha$-Ts [3].

The negative meta-analysis outcome exposed flaws in the current knowledge of vitamin E. Literature review and re-interpretation to update the knowledge of vitamin $\mathrm{E}$ is appropriate and necessary for future research direction for the benefits and well-being of mankind.

Vitamin E metabolism

Numerous reviews were published on vitamin E (or more precisely, on $\alpha$-T) metabolism [6, 26, 34, 37, 38, 66, 81, 84, $85,92]$. Isotopic labeling, chemical inhibitors and genetically defect subjects provided valuable data for understanding the metabolism of $\alpha$-T. However, it is unfortunate that $\alpha$-T metabolism have been overgeneralized and extrapolated to all forms of vitamin $\mathrm{E}$, some of which are incorrect.

Vitamin E together with food is subjected to normal digestive processes at oral cavity, esophagus and stomach, followed by gastric emptying, biliary and pancreatic actions before moving to the small intestine for absorption. As mentioned earlier, esters of $\alpha$-T (acetate and succinate) are hydrolyzed into free $\alpha-\mathrm{T}$ and are absorbed without 
re-esterification. Presumably, other forms of vitamin E behave similarly.

Vitamin $\mathrm{E}$ absorption is the transport of vitamin $\mathrm{E}$ from intestinal lumen to plasma via mesenteric lymphatic pathway. Absorption of $\alpha-T$ via the portal vein was not observed [4].

\section{Secretion in lipoproteins}

Vitamin $\mathrm{E}$ is fat soluble and requires lipoproteins as carrier in lymphatic and blood circulatory systems. $\alpha$-T is almost exclusively secreted in chylomicrons in rats. Intraduodenal administration with isotopic labeled $\alpha$-T on mesenteric lymph duct-cannulated rats indicated approximately $99 \%$ of the absorbed $\alpha-\mathrm{T}$ was associated with chylomicrons, whereas only $0.5 \%$ of the absorbed $\alpha$-T was found in highdensity lipoproteins (HDL) in intestinal lymph [4].

Microsomal triglyceride transfer protein (MTP), adequate lipids and fatty acid are required for enterocytes to secrete $\alpha-T$ in apolipoprotein (apo) B-48-containing triglyceride-rich lipoproteins: chylomicrons and very lowdensity lipoproteins (VLDL) [2]. In the absence of fatty acid but with adequate lipid supply, enterocytes secrete $\alpha$-T mainly in intermediate-density lipoproteins (IDL) [2]. In the absence of lipids, practically, no secretion of $\alpha$-T in chylomicrons was observed [2]. Abetalipoproteinemia patients are unable to secrete $\alpha$-T in chylomicrons due to mutation in the microsomal triglyceride transfer protein gene (Mttp), whereas hypobetalipoproteinemia patients have low apo B gene [31]. Inhibitors for protein secretion or protein transport, such as brefeldin A and monensen, inhibit $\alpha$-T secretion in chylomicrons [2].

Enterocytes can secrete $\alpha$-T in nascent apo A-I-containing small HDLs independent of MTP or food availability, but this pathway is enhanced by exogenous HDL supply and inhibited by glyburide, an ATP-binding cassette transporter inhibitor. It was suggested that $\alpha$-T entered into small HDL particles by simple efflux in enterocytes [2].

However, the assembly of Ts and lipids prior to secretion in chylomicrons may be mediated by scavenger class B type 1 (SR-B1). SR-B1 is expressed at high level in the intestine and is involved in the trafficking of micellar vitamin E across enterocytes [65]. Anti-human SR-B1 antibodies and BLT1 (a chemical inhibitor of lipid transport via SR-B1) blocked up to $80 \%$ of $\alpha$-T and $\gamma$-T uptake and blocked up to $30 \%$ of the apical $\alpha$-T efflux [65]. Bioavailability of $\gamma$-T in mice with intestinal overexpression of SR-B1 was 2.7 folds higher than that of the wild-type mice. $\alpha-\mathrm{T}$ and $\gamma$-T compete for transport by SR-B1 [65].

After secretion by enterocytes, vitamin $\mathrm{E}$ in chylomicrons and small HDLs is transported from mesenteric lymph to the blood circulatory system via thoracic duct and subclavian vein.
Small HDLs pick up other lipids upon maturation and can be delivered directly to the peripheral tissues via SR-BI selective vitamin E uptake without repacking into VLDL in the liver. Small HDL can transfer $\alpha$-T to circulating VLDL and low-density lipoprotein (LDL) [83].

The chylomicron remnant receptors cannot directly uptake the newly formed triglyceride-rich chylomicrons into the liver [1]. Newly formed chylomicrons deliver triglycerides to muscles and adipose tissues via lipoprotein lipase (LPL) delipidation. After 80-90\% of the triglycerides are hydrolyzed, the resultant chylomicron remnant can then be bound and taken up into the liver by the remnant receptor via apo E [96]. After internalized into the hepatocytes, apo B-48 is digested and vitamin $\mathrm{E}$ is released into the cytoplasm for the action of $\alpha$-TTP. Each molecule of $\alpha$-T is sequestered deep inside an $\alpha$-TTP molecule $[49,51]$. Unbound vitamin $\mathrm{E}$ is subjected to rapid catabolism. The apo B-48 lipoprotein lacks the LDL receptor-binding domain, rapidly catabolized and apo B-48 is normally not detectable in the LDL [96]. The normal half-time removal of apo B-48-containing chylomicron in plasma is short, only about 5-15 min, whereas for LPL-deficient subjects, there is no removal of apo B-48 for several hours [75]. Only one apo B-48 is found in a chylomicron, and apo B-48 is not known to undergo exchange with other lipoproteins.

\section{Repacking vitamin $\mathrm{E}$ in the liver}

$\alpha$-TTP in the liver plays an important role in $\alpha$-T absorption. Mutation of $\alpha$-TTP gene can cause $\alpha$-T deficiency leading to neurodegenerative disease ataxia with isolated vitamin E deficiency (AVED) [19, 25, 58].

$\alpha$-TTP discriminately repacks (depending on the relative binding affinities) vitamin $\mathrm{E}$ originated from chylomicron remnants with apo B-100 and other components into nascent VLDL. VLDL also delivers triglycerides to muscles and adipose tissue via LPL delipidation, and the resulting VLDL remnant is the IDL. Further delipidation of IDL forms LDL. Unlike chylomicrons remnants, IDL and LDL have LDL-receptor-binding domains, enable receptormediated lipoprotein endocytosis, facilitating uptake of vitamin $E$ into the peripheral tissues and catabolism of the apo B-100. The normal half-time removal of apo B-100containing lipoproteins in plasma is slightly longer than that of apo B-48, about 15-25 min [75].

Repeated re-packing $\alpha$-T (from circulating and/or that stored in the liver) into VLDL by the action of $\alpha$-TTP for re-circulation explains the long residence time of $\alpha$-T. Other forms of vitamin $\mathrm{E}$ disappeared rapidly from plasma and were no longer detectable within $24 \mathrm{~h}$ after oral administration.

In mice with inactivated Mttp expression, no VLDL is secreted in the liver. Such mice have lower plasma $\alpha$-T, 
absence of apo B-100 lipoproteins and higher accumulation of $\alpha-T$ (and fat) in the liver. However, it was reported that uptake of $\alpha$-T in other tissues of the mice was only slightly delayed and not affected otherwise [52]. Repacking $\alpha-\mathrm{T}$ in chylomicron remnants into nascent VLDL in the mouse seemed unnecessary for $\alpha$-T uptake. Re-examining the raw data indicated that HDL was the only lipoprotein involved in the plasma after 1 day, and small proportions of $\alpha$-T appeared to have been transferred to non-HDL lipoproteins 14 and 28 days after the mice were fed with deuterated $\alpha$-T and $\gamma$-T. Deuterated $\alpha$-T was still preferentially absorbed over the $\gamma$-T, indicated that $\alpha$-TTP was in action.

It is reasonable to postulate that hepatocytes can resecrete $\alpha$-T in nascent HDL for Mttp-inactivated mice, similar to secretion of small HDLs by enterocytes. This is consistent with the observations that majority of $\alpha$-T was found in chylomicrons (presumably apo B-48-containing) after $2 \mathrm{~h}$ and shifted to HDL after $6 \mathrm{~h}$ of feeding, absence of apo B-100 lipoproteins in the plasma, all deuterated $\alpha$-T was in the HDLs 1 day after oral intake and the delivery of deuterated $\alpha$-T to peripheral tissues were similar to that of control mice.

Repacking $\alpha$-T into lipid-poor HDLs has not been reported for $\alpha$-TTP and may be limited by the availability of apo A-I for secretion in HDLs. Smaller capacity of $\alpha$-T in each HDL particle when compared to chylomicrons also may be slowing subsequent $\alpha$-T uptake into peripheral tissues and causing $\alpha$-T accumulation in the liver with reduced hepatic re-circulation. This can explain the delay in deuterated $\alpha$-T uptake to peripheral tissues 1 day after the oral intake and lower $\alpha$-T plasma level when compared to control mice.

The observation in mice with inactivated Mttp expression demonstrated that $\alpha$-T and $\gamma$-T bioavailability at various tissues was not affected by low plasma levels. The similar distribution in various tissues also indicated that $\alpha$-T and $\gamma$-T were taken into the tissues via similar receptormediated lipoprotein endocytosis as the control mice.

\section{$T_{3}$ s are different from $\alpha$-T, they are impressive and promising in chemo-prevention}

\section{Bioavailability in rodents}

Rats fed with $\alpha-\mathrm{T}_{3}$ singly had higher bioavailability in some tissues (epididymal fat, perirenal adipose tissue and skin) when compared to that fed singly with equal amount of $\alpha-T$ [33, 39]. This contradicted the in vitro relative binding affinity with $\alpha$-TTP, which natural $\alpha-\mathrm{T}_{3}$ was reported to have only $12.4 \%$ that of natural $\alpha$-T [29]. However, the bioavailability of $\alpha-T_{3}$ was significantly depressed and was always lower than that of $\alpha$-T when the rats were co-supplemented with equal amount of $\alpha$-T and $\alpha-\mathrm{T}_{3}[33,39]$. Also observed was that $\alpha-\mathrm{T}$ was more evenly distributed in the peripheral tissues, whereas $\alpha-T_{3}$ was preferentially distributed in epididymal fat, perirenal adipose tissue and skin. Higher urinary metabolite $\alpha$-carboxyethyl-6-hydroxychroman ( $\alpha$-CEHC) secretion was observed when the rats were on $\alpha-T_{3}$ and $\alpha$-T co-supplementation diet [33].

Rats fed with $\gamma-\mathrm{T}_{3}$ singly also have similar high $\gamma-\mathrm{T}_{3}$ level in the same tissues (epididymal fat, perirenal adipose tissue and skin), but these $\gamma-\mathrm{T}_{3}$ levels are lower than the $\alpha-\mathrm{T}_{3}$ levels for rats fed with equal amount of $\alpha-\mathrm{T}_{3}$ diet [33]. But the bioavailability of $\gamma-\mathrm{T}_{3}$ was not depressed when the rats were co-supplemented with equal amount of $\alpha$-T and $\gamma-\mathrm{T}_{3}$ [33]. No change was observed in urinary $\gamma$-CEHC levels for supplementation with $\gamma-\mathrm{T}_{3}$ singly or co-supplementation with $\alpha$-T.

The medium and long-term studies in rodents are consistent with the hypothesis that $\alpha-\mathrm{T}$ is practically secreted in chylomicrons only, whereas $\alpha-T_{3}$ has an additional pathway via secretion in lipid-poor small HDLs. The small HDL pathway delivered $\alpha-\mathrm{T}_{3}$ to selective vital organs via selective vitamin $\mathrm{E}$ uptake, independent of $\alpha$-TTP actions. The uptake via small HDLs is dependent on the availability of scavenger receptors, which is more abundant in the fatty tissues. Bioavailability via chylomicrons is expected to be evenly distributed, as LDLreceptors are available in all tissues. Comparison with the distribution of $\alpha$-T and $\gamma$-T in the case of inactivated Mttp mice, the uptake of vitamin $\mathrm{E}$ in HDLs taken place via different mechanisms. Uptake of vitamin $\mathrm{E}$ in small HDLs secreted by enterocytes was mainly via scavenger receptor-mediated selective vitamin E uptake, whereas Ts in chylomicrons repacked into HDLs for inactivated Mttp mice was mainly via LDL-receptor-mediated endocytosis. Small HDLs secreted by enterocytes therefore appeared to be different from circulating HDLs. It is not known whether small HDLs contain apo $\mathrm{E}$ that is needed for LDL-receptor binding.

When $\alpha-T_{3}$ is supplemented singly, $\alpha-T_{3}$ can bind with $\alpha$-TTP with little competition from re-circulating $\alpha$-T. When co-supplemented with $\alpha$-T, the liver cytoplasm is saturated with $\alpha$-T and $\alpha-\mathrm{T}_{3}$ is discriminated by $\alpha$-TTP, resulting in a lower bioavailability when compared to that fed with $\alpha-\mathrm{T}_{3}$ singly. This is consistent with higher urinary metabolite $\alpha$-CEHC was observed for co-supplementation. Comparing urinary CEHC contents in rats fed with $\alpha-\mathrm{T}_{3}$ and $\gamma-\mathrm{T}_{3}$ singly, $\gamma$-CEHC was at least twice that of $\alpha$-CEHC. $\gamma$-CEHC did not increase by co-supplementation of $\gamma-\mathrm{T}_{3}$ with $\alpha-\mathrm{T}$, indicating that $\gamma-\mathrm{T}_{3}$ has very low binding affinity with $\alpha$-TTP. Binding affinity of $\delta$-T 3 with $\alpha$-TTP has not been reported, but it is predicted to be slightly lower than that of $\gamma-\mathrm{T}_{3}$. 
From the data displayed in the reported figure (not shown here) [33], the extent of depression in bioavailability varied significantly for different tissues. A rough estimate indicated that the depression of $\alpha-\mathrm{T}_{3}$ by $\alpha$-T co-supplementation in rats was $30,47,58$ and $71 \%$ for perirenal adipose tissue, epididymal fat, skin and muscle, respectively. Assuming that the depression in bioavailability was totally due to discrimination based on $\alpha$-TTP binding affinity of $\alpha-\mathrm{T}_{3}$ (12.4\% of $\alpha$-T), the estimated proportion of $\alpha-\mathrm{T}_{3}$ secreted via chylomicrons was $34,54,66$ and $81 \%$ for perirenal adipose tissue, epididymal fat, skin and muscle, respectively, and the balance of $\alpha-T_{3}$ was then from small HDL pathway. The bioavailability of $\gamma-T_{3}$ reported for various tissues can be interpreted as that originated from secretion in small HDLs as that secreted in chylomicrons were practically discriminated due to very low binding affinity with $\alpha$-TTP.

Female $\alpha$-TTP-deficient mice are infertile due to vitamin $\mathrm{E}$ deficiency. The impaired placenta of a pregnant mouse with marked reduction of labyrinthine trophoblasts cannot support the survival of embryos transferred from fertilized eggs of a wild-type mouse [36]. Oral supplementation with $\alpha-\mathrm{T}_{3}$, but not $\alpha$-T, restored fertility of $\alpha$-TTP-deficient mice [39]. This is a direct evidence that $\alpha-\mathrm{T}_{3}$ can be absorbed via an $\alpha$-TTP independent pathway, such as by secretion in the small HDLs. Although $\alpha-\mathrm{T}_{3}$ levels in the blood and liver are lower than that of $\alpha-T$, higher levels of $\alpha-T_{3}$ than $\alpha-T$ were observed in adipose tissue, skin, vastus lateralis, heart and spinal cord in both the $\alpha$-TTP-deficient female and the wild-type male mice, whereas the levels appeared to have no difference in lung and brain after supplementation with a mixture containing about equal amount of $\alpha-T$ and $\alpha-T_{3}$. Liver may play a pivotal role in the metabolism for $\alpha$-T but not for $T_{3}$ as reflected in relatively low levels of $T_{3}$ in the liver when compared to that in peripheral tissues and the high $\alpha$-T level.

\section{Reinterpreting human single-dose oral administration} studies

Human single-dose oral administration studies on palm TRF had been reported [15, 94]. A third report [40] on oral administration of TRF is not used due to major discrepancy in the analysis of $\mathrm{T}_{3}$ composition.

Dual $\mathrm{T}_{3}$ concentration maxima $\left(C_{\max }\right)$ in human blood plasma were observed under fed conditions, whereas only a single $\mathrm{T}_{3} C_{\max }$ was observed under fasting conditions [94]. The first and second peaks of $\mathrm{T}_{3}$ in blood plasma with $C_{\max }$ at about 3.5 and $6.0 \mathrm{~h}$, respectively, after TRF oral administration under fed condition can be postulated as due to $\mathrm{T}_{3}$ secretion in chylomicrons and small HDLs, respectively. Chylomicron pathway requires shorter time to achieve $C_{\max }$ than that of HDL pathway possibly due to a few reasons. First, chylomicrons have larger capacity than small HDLs. Secondly, under fed conditions, there were sufficient lipids and fatty acids for chylomicrons secretion and lastly, secretion in chylomicrons may be mediated by efficient mechanism such as that by SR-B1 [65]. Exogenous HDLs significantly enhanced $\alpha$-T secretion in small HDLs by enterocytes, it is likely that of $\alpha$-T entered into small HDLs by simple efflux [2]. This suggested that assembly of $\mathrm{T}_{3}$ in small HDL can be a limiting factor. $\mathrm{T}_{3}$ secretion may be delayed due to limiting apo A-I availability. Data from rat jejunum showed that apo A-I content increased sharply over the 6-h monitoring period during fat absorption, whereas there was little change in the apo B content after $1 \mathrm{~h}$ [73]. Since apo A-I is a common component in both chylomicrons and small HDL, SR-B1mediated assembly may be more efficient in competing for apo A-I than the simple efflux mechanism.

From the figure displayed in that report [94] (not shown here), the single $C_{\max }$ at about $3.8-4.3 \mathrm{~h}$ after oral administration should be reinterpreted as plasma $\mathrm{T}_{3}$ originated from the small HDLs as there should hardly be any secretion of $\mathrm{T}_{3}$ via chylomicrons pathway under fasting conditions. A shorter time to reach $C_{\max }$ for the small HDL pathway under fasting conditions is logical as gastric emptying should be shorter than that under the fed conditions.

The 2.5, 2.8 and 2.9 times higher absorption under the fed conditions (over the fasting conditions) for $\delta-\mathrm{T}_{3}, \alpha-\mathrm{T}_{3}$ and $\gamma-\mathrm{T}_{3}$, respectively, were contributed by an improved absorption under the fed conditions and also due to the additional chylomicron absorption pathway.

The lag time of absorption indicates the time from oral intake to detection in the blood. The lag time reported [94] for $\mathrm{T}_{3} \mathrm{~s}$ was less than $1 \mathrm{~h}$ under the fed conditions. The reported lag time was likely overestimated as the first timepoint was $1 \mathrm{~h}$ after oral administration. Higher sampling frequency at initial time-points will provide a more accurate lag time. Short lag time and rapid blood circulation rate implied that the time in secretion of $\mathrm{T}_{3} \mathrm{~s}$ in chylomicrons and small HDLs determines the time to achieve the respective $C_{\max }$.

Calculation using area under the curves divided by the dosage supplemented of the reported data [15, 94] indicated that absorption of $\alpha-\mathrm{T}_{3}>\gamma-\mathrm{T}_{3} \geq \delta-\mathrm{T}_{3}$. Significant higher absorption of $\alpha-\mathrm{T}_{3}$ (about twice that of $\gamma-\mathrm{T}_{3}$ ) revealed there is discrimination in absorption of $\mathrm{T}_{3}$. Preferential absorption of $\alpha-\mathrm{T}_{3}$ over $\gamma-\mathrm{T}_{3}, \delta-\mathrm{T}_{3}$ and $\alpha$-T had been reported for thoracic duct-cannulated rats [32].

Vitamin E contents in plasma lipoproteins provided more information [15]. $\alpha$-T content is highest in the HDL, followed by LDL, and lowest in the triglyceride-rich particles (TRP). However, the background (at $0 \mathrm{~h}$ ) $\alpha$-T contents in all the lipoproteins are relatively high. While $\alpha$-T 
content in chylomicrons drops below the $0 \mathrm{~h}$ level, $\alpha$-T contents in LDL and HDL remain high, although on slow declining trend at $24 \mathrm{~h}$. On the other hand, the background $\mathrm{T}_{3} \mathrm{~s}$ are practically undetectable in all the lipoproteins. Also $\mathrm{T}_{3} \mathrm{~s}$ are undetectable after $24 \mathrm{~h}$ of oral administration. $\mathrm{T}_{3} \mathrm{~S}$ are mainly distributed in the chylomicrons and HDL.

More vitamin E in the plasma was found in HDL than in LDL. This is in contrast with cholesterol, which is mainly found in LDL. The concentration of various forms of vitamin $\mathrm{E}$ in plasma is time dependent, and blood sample taken under fasting condition is non-representative of the vitamin $\mathrm{E}$ status in human body. The absorption of $\alpha-\mathrm{T}$ is complicated by high background level at $0 \mathrm{~h}$ and also hepatic re-circulation due to $\alpha$-TTP. High level of $\alpha$-T in the plasma does not necessarily mean higher bioavailability of vitamin $E$ in the peripheral tissues because of hepatic re-circulation. Vitamin $\mathrm{E}$ in plasma lipoproteins is complicated by hepatic recycling, exchangeable apolipoproteins and transfer of vitamin E between lipoproteins.

\section{Bioavailability in humans}

There is hardly any $T_{3}$ bioavailability data for humans except a recent report [57] revealed that adipose tissue surrounding human breast benign tumors had higher $\mathrm{T}_{3}$ contents $\left(27 \pm 8,19 \pm 6\right.$ and $2.1 \pm 0.7 \mu \mathrm{mol} / \mathrm{kg}$ for $\alpha-\mathrm{T}_{3}$, $\gamma-\mathrm{T}_{3}$ and $\delta-\mathrm{T}_{3}$, respectively) when compared to that for malignant tumors $(17 \pm 10,15 \pm 6$ and $1.3 \pm 0.8 \mu \mathrm{mol} / \mathrm{kg}$ for $\alpha-\mathrm{T}_{3}, \gamma-\mathrm{T}_{3}$ and $\delta-\mathrm{T}_{3}$, respectively). It is interesting to note the levels of total $\mathrm{T}_{3}$ were quite substantial (48 \pm 14 and $33 \pm 15 \mu \mathrm{mol} / \mathrm{kg}$, respectively) in view that these subjects were not supplemented with $\mathrm{T}_{3}$ but acquired them via normal dietary intake where palm oil is the most common cooking oil for the subjects.

\section{Removal and catabolism}

Unabsorbed vitamin $\mathrm{E}$ is removed in the feces. In the liver, vitamin $\mathrm{E}$ unbound to $\alpha$-TTP is excreted into the bile or undergoes catabolism initiated by cytochrome P450-mediated $\omega$-hydroxylation, followed by $\beta$-oxidation, forms respective $\mathrm{CEHC}$ as the main metabolites and excretes through urine [7] Vitamin $\mathrm{E}$ is also removed through the skin. $\alpha-\mathrm{T}$ and $\gamma-\mathrm{T}$ are excreted in sebum by stratum corneum [80] and also found in shed skin [79].

\section{Chemo-prevention}

The chemo-preventive role of $\mathrm{T}_{3}$ is a subject of active research for the past few years. It is not the intention here to review on the chemo-preventive properties of $T_{3} \mathrm{~s}$. A book [90] and a review [72] summarized the preliminary roles of $\mathrm{T}_{3} \mathrm{~s}$ in chemo-prevention. Only two points will be discussed here: potency and interactions with drugs and supplements.

Generally, the decreasing order of potency are $\delta-\mathrm{T}_{3}>$ $\beta-\mathrm{T}_{3}>\gamma-\mathrm{T}_{3}>\alpha-\mathrm{T}_{3}$ for the prevention of certain cancers and cardiovascular diseases [14, 46, 53-56, 60]. Table 1 illustrates that the order of potency in inhibiting preneoplastic (CL-S1), neoplastic (-SA) and malignant (+SA) mouse mammary epithelial cell growth was $\delta-\mathrm{T}_{3}>$ $\gamma-\mathrm{T}_{3}>\alpha-\mathrm{T}_{3}>\mathrm{TRF}>\delta$-T, whereas $\gamma-\mathrm{T}$ and $\alpha-\mathrm{T}$ were ineffective [46]. There are exceptions to this general order of potency. $\gamma-\mathrm{T}_{3}$ was reported to have slightly better potency than $\delta$ - $\mathrm{T}_{3}[23,95]$. For neuroprotection, at $100 \mathrm{nM}$ level, $\alpha-\mathrm{T}_{3}$ has the highest potency, but at higher concentration of $250 \mathrm{nM}, \gamma-\mathrm{T}_{3}$ has the same potency as $\alpha-\mathrm{T}_{3}$ [71].

$\alpha-\mathrm{T}$ was reported as a Tamoxifen antagonist for breast cancer therapy $[23,61,62]$, whereas $\mathrm{T}_{3} \mathrm{~s}$, especially $\delta$-T and $\gamma-\mathrm{T}_{3}$, shown strong synergistic anticancer effect with Tamoxifen [23], statin [88, 89] and celecoxib [74]. $\alpha$-T was also reported to attenuate the cholesterol lowering effect of $\mathrm{T}_{3}$ [64].

$\alpha$-T has antagonistic effect on $T_{3} s$ for the degenerative diseases chemo-prevention. This can be seen by comparing the calculated weighted average of the potency data $\left(\mathrm{IC}_{50}\right.$ or $\mathrm{LD}_{50}$ or $\mathrm{EC}_{50}$ ) of individual $\mathrm{T}_{3} \mathrm{~s}$ with the observed TRF data. In all cases, so far, the calculated potency for $\mathrm{T}_{3}$ mixtures is better than that observed for TRF due to the presence of $\alpha-\mathrm{T}$ as an antagonist. Table 1 illustrates the antagonistic effect of $\alpha$-T on $\mathrm{T}_{3}$ using mouse mammary epithelial cells [46] as an example. Table 1 clearly demonstrated that the observed potency is poorer than the calculated potency based on the TRF composition, assuming that $\alpha-\mathrm{T}$ is non-confounding.

It is noteworthy to highlight that TRF used in most of the research contains more than $20 \%$ of $\alpha$-T, expressed as percentage of the total vitamin E content. Although such TRF is still showing positive results as shown in Table 1,

Table 1 Effects of vitamin E and TRF on preneoplastic (CL-S1), neoplastic $(-\mathrm{SA})$ and malignant $(+\mathrm{SA})$ mouse mammary epithelial cell growth $\left(\mathrm{IC}_{50}\right.$ in $\left.\mu \mathrm{M}\right)$ [46]

\begin{tabular}{lrrr}
\hline Vitamin E & CL-S1 & - SA & + SA \\
\hline$\alpha-\mathrm{T}$ & $>120$ & $>120$ & $>120$ \\
$\gamma-\mathrm{T}$ & $>120$ & $>120$ & $>120$ \\
$\delta-\mathrm{T}$ & 55 & 47 & 23 \\
$\alpha-\mathrm{T}_{3}$ & 12 & 7 & 5 \\
$\gamma-\mathrm{T}_{3}$ & 8 & 5 & 4 \\
$\delta-\mathrm{T}_{3}$ & 7 & 4 & 3 \\
TRF observed & 13 & 7 & 6 \\
TRF calculated & 9 & 5 & 4 \\
\hline TRF contains $20.2 \%$ & $16.8 \%$ & $\alpha-T_{3,}$ &
\end{tabular}

TRF contains $20.2 \% \alpha-\mathrm{T}, 16.8 \% \alpha-\mathrm{T}_{3}, 44.9 \% \gamma-\mathrm{T}_{3}$ and $14.8 \% \delta-\mathrm{T}_{3}$. TRF calculated is the weighted average of $\mathrm{IC}_{50}$ calculated based on individual $T_{3}$ assuming $\alpha$-T is non-confounding 
both bioavailability and potency can be improved by eliminating $\alpha$-T or at least minimizing it.

\section{Future direction}

From nutritional viewpoint, there is no necessity to supplement with $\alpha$-T [28]. From pharmacologic viewpoint, Fig. 2 has clearly revealed that $\alpha-T$ supplement is undesirable, it does more harm than good. It is unfortunate to see that after nearly nine decades since the discovery of vitamin $\mathrm{E}$, the basic knowledge of vitamin $\mathrm{E}$ is still yet to be established, with errors and misnomers used in major scientific journals, reference books and expert opinions. Higher mortality for human subjects consuming natural $\alpha$-T supplement is too high a price for mankind!

The dietary reference intakes for vitamin $E$ were made on wrong assumptions that $2 R-\alpha-\mathrm{T}$ stereoisomers are the only relevant forms of vitamin $\mathrm{E}$. In view of the clear evidence that natural $\alpha$-T supplementation significantly increases the all-cause mortality and $\mathrm{T}_{3} \mathrm{~s}$ can be absorbed via $\alpha$-TTP-independent pathway, there is a need to review critically on the dietary reference intakes recommendations. It is not known whether $\alpha$-T is still essential to humans in long terms, $\alpha-\mathrm{T}_{3}$ diet appeared to produce healthy rats over five generations [39]. $\mathrm{T}_{3}$ may be an alternative for mega-doses of $\alpha$-T supplementation and potentially a more efficient solution for patients suffering from vitamin E deficiencies. Experimental data demonstrated that $\mathrm{T}_{3} \mathrm{~s}$ have good chemo-preventive potencies against various degenerative diseases, whereas that for $\alpha$-T is ineffective.

It is timely for $\mathrm{T}_{3}$ or TRF to be evaluated clinically. The chemo-preventive and chemotherapeutic potential of $\mathrm{T}_{3}$ should be explored in view of the positive in vitro and in vivo studies, and to a very limited extent, human intervention studies. Mankind has not benefited from vitamin $\mathrm{E}$ for nearly nine decades after its discovery, mainly due to misconceptions and misinterpretation of inadequately designed experiments. It is hoped that clinical trials performed on the right form of vitamin $\mathrm{E}$ shall provide chemo-prevention of degenerative diseases for the mankind. Evidently, the high binding affinity of $\alpha-T$ with $\alpha$-TTP becomes an obstruction to bioavailability of other forms of vitamin E. From both bioavailability and chemopreventive potency viewpoints, a suitable material for clinical evaluation is TRF free from or containing minimum amount of $\alpha-\mathrm{T}$.

Acknowledgments The author thanks the ASAP Study Group for providing unpublished mortality datum on ASAP randomized controlled trial for $\alpha$-T supplementation singly. The author also thanks Palm Nutraceuticals Sdn. Bhd. for permission to publish this paper.

\section{References}

1. Abe C, Ikeda S, Uchida T, Yamashita K, Ichikawa T (2007) Triton WR1339, an inhibitor of lipoprotein lipase, decreases vitamin $\mathrm{E}$ concentration in some tissues of rats by inhibiting its transport to liver. J Nutr 137:345-350

2. Anwar K, Iqbal J, Hussain MM (2007) Mechanisms involved in vitamin $\mathrm{E}$ transport by primary enterocytes and in vivo absorption. J Lipid Res 48:2028-2038

3. Bjelakovic G, Nikolova D, Glund LL, Simonetti RG, Glund C (2007) Mortality in randomized trials of antioxidant supplements for primary and secondary prevention-systematic review and meta-analysis. JAMA 297:842-857

4. Bjørneboe A, Bjørneboe G-EA, Bodd E, Hagen BF, Kveseth N, Drevon CA (1986) Transport and distribution of $\alpha$-tocopherol in lymph, serum and liver cells in rats. Biochim Biophys Acta 889:310-315

5. Boaz M, Smetana S, Weinstein T, Matas Z, Gafter U, Iaina A, Knecht A, Weissgarten Y, Brunner D, Fainaru M, Green MS (2000) Secondary prevention with antioxidants of cardiovascular disease in endstage renal disease (SPACE): randomised placebocontrolled trial. Lancet 356:1213-1218

6. Brigelius-Flohé R, Kelly FJ, Salonen JT, Neuzil J, Zingg JM, Azzi A (2002) The European perspective on vitamin E, current knowledge and future research. Am J Clin Nutr 76:703-716

7. Brigelius-Flohé R (2003) Vitamin E and metabolism. Biochem Biophys Res Comm 305:737-740

8. Brown MS, Goldstein JL (1983) Lipoprotein metabolism in the macrophage: implications for cholesterol deposition in atherosclerosis. Annu Rev Biochem 52:223-261

9. Burton GW, Ingold KU, Foster DO, Cheng SC, Webb A, Hughes $\mathrm{L}$ (1988) Comparison of free $\alpha$-tocopherol and $\alpha$-tocopheryl acetate as sources of vitamin $\mathrm{E}$ in rats and humans. Lipids 23:834-840

10. Cheeseman KH, Holley AE, Kelly FJ, Wasil M, Hughes L, Burton G (1995) Biokinetics in humans of $R R R$ - $\alpha$-tocopherol: the free phenol, acetate ester, and succinate ester forms of vitamin $E$. Free Radic Biol Med 19:591-598

11. Chun J, Lee J, Ye L, Exler J, Eitenmiller RR (2006) Tocopherol and tocotrienol contents of raw and processed fruits and vegetables in the United States diet. J Food Compos Anal 19:196-204

12. Collins EG, Langbein WE, Orebaugh C, Bammert C, Hanson K, Reda D, Edwards LC, Littooy FN (2003) Polestriding exercise and vitamin $\mathrm{E}$ for management of peripheral vascular disease. Med Sci Sports Exerc 35:384-393

13. Desnuelle C, Dib M, Garrel C, Favier A, ALS RiluzoleTocopherol Study Group (2001) A double-blind, placebo-controlled randomized clinical trial of alpha-tocopherol (vitamin E) in the treatment of amyotrophic lateral sclerosis. Amyotroph Lateral Scler Other Motor Neuron Disord 2:9-18

14. Eitsuka T, Nakagawa K, Miyazawa T (2006) Down-regulation of telomerase activity in DLD-1 human colorectal adenocarcinoma cells by tocotrienol. Biochem Biophys Res Comm 348:170-175

15. Fairus S, Nor RM, Cheng HM, Sundrum K (2006) Postprandial metabolic fate of tocotrienol-rich vitamin $\mathrm{E}$ differs significantly from that of $\alpha$-tocopherol. Am J Clin Nutr 84:835-842

16. Fiorentino A, Mastellone C, D'Abrosca B, Pacifico S, Scognamiglio M, Cefareli G, Caputo R, Monaco P (2009) $\delta$-Tocomonoenol: a new vitamin E from kiwi (Actinidia chinensis) fruits. Food Chem 115:187-192

17. de Gaetano G, Collaborative Group of The Primary Prevention Project (PPP) (2001) Low-dose aspirin and vitamin E in people at cardiovascular risk: a randomised trial in general practice. Lancet 357:89-95 
18. Gillilan RE, Mondell B, Warbasse JR (1997) Quantitative evaluation of vitamin $\mathrm{E}$ in the treatment of angina pectoris. Am Heart J 93:444-449

19. Gotoda T, Arita M, Arai H, Ionue K, Yokota T, Fukuo Y, Yazaki Y, Yamada N (1995) Adult-onset spinocerebellar dysfunction caused by a mutation in the gene for the $\alpha$-tocopherol-transfer protein. N Engl J Med 333:1313-1318

20. Graat JM, Schouten EG, Kok FJ (2002) Effect of daily vitamin E and multivitamin-mineral supplementation on acute respiratory tract infections in elderly persons: a randomized controlled trial. JAMA 288:715-721

21. Graf M, Ecker D, Horowski R, Kramer B, Riederer P, Gerlach M, Hager C, Ludolph AC, The German Vitamin E/ALS Study Group (2005) High dose vitamin E therapy in amyotrophic lateral sclerosis as add-on therapy to riluzole: results of a placebo-controlled double-blind study. J Neural Transm 112:649-660

22. Gruppo Italiano per lo Studio della Sopravvivenza nell'Infarto miocardico (GISSI) (1999) Dietary supplementation with n-3 polyunsaturated fatty acids and vitamin $\mathrm{E}$ after myocardial infarction: results of the GISSI-Prevenzione trial. Lancet 354:447-455

23. Guthrie N, Gapor A, Chambers AF, Carroll KK (1997) Inhibition of proliferation of estrogen receptor-negative MDA-MB-435 and positive MCF-7 human breast cancer cells by palm oil tocotrienols and tamoxifen, alone and in combination. J Nutr 127:544S$548 \mathrm{~S}$

24. Harman D (1956) Aging: a theory based on free radical and radiation chemistry. J Gerontol 11:298-300

25. Hentati A, Deng H-X, Hung W-Y, Nayer M, Ahmad MS, He X, Tim R, Stumpf DA, Siddique T (1996) Human $\alpha$-tocopherol transfer protein: gene structure and mutations in familial vitamin E deficiency. Ann Neurol 39:295-300

26. Herrera E, Barbas C (2001) Vitamin E: action, metabolism and perspectives. J Physiol Biochem 57:43-56

27. Hodis HN, Mack WJ, Labree L, Mahrer PR, Sevanian A, Liu C-R, Liu C-H, Hwang J, Selzer RH, Azen SP, VEAPS Research Group (2002) Alpha-tocopherol supplementation in healthy individuals reduces low-density lipoprotein oxidation but not atherosclerosis: the Vitamin E Atherosclerosis Prevention Study (VEAPS). Circulation 106:1453-1459

28. Horwitt MK (2001) Critique of the requirement for vitamin E. Am J Clin Nutr 73:1003-1005

29. Hosomi A, Arita M, Sato Y, Kiyose C, Ueda T (1997) Affinity for $\alpha$-tocopherol transfer protein as determinant of the biological activities of vitamin E analogs. FEBS Lett 409:105-108

30. Huang H-Y, Appel LJ (2003) Supplementation of diets with $\alpha$-tocopherol reduces serum concentrations of $\gamma$ - and $\delta$-tocopherol in humans. J Nutr 133:3137-3140

31. Hussain MM, Shi J, Dreizen P (2003) Microsomal triglyceride transfer protein and its role in apoB-lipoprotein assembly. J Lipid Res 44:22-32

32. Ikeda I, Imasato Y, Sasaki E, Sugano M (1996) Lymphatic transport of alpha-, gamma- and delta-tocotrienols and alphatocopherol in rats. Int J Vit Nutr Res 66:217-221

33. Ikeda S, Tohyama T, Yoshimura H, Hamamura K, Abe K, Yamashita K (2003) Dietary $\alpha$-tocopherol decreases $\alpha$-tocotrienol but not $\gamma$-tocotrienol concentration in rats. J Nutr 133:428-434

34. Institute of Medicine (2000) Dietary reference intake of vitamin C, vitamin E, selenium and carotinoids. Food and Nutrition Board. National Academy Press, Washington DC, pp 186-283

35. IUPAC-IUB Joint Commission on Biochemical Nomenclature (JCBN) Nomenclature of tocopherols and related compounds. Recommendations 1981. [http://www.chem.qmul.ac.uk/iupac/misc/ toc.html]

36. Jishage $\mathrm{K}$, Arita M, Igarashi K, Iwata $\mathrm{T}$, Watanabe M, Ogawa M, Ueda O, Kamada N, Inoue K, Arai H, Suzuki H (2001)
$\alpha$-Tocopherol transfer protein is important for the development of placental labyrinthine trophoblasts in mice. J Biol Chem 276:1669-1672

37. Kaempt-Rotzoll DE, Traber MG, Arai H (2003) Vitamin E and transfer proteins. Curr Opin Lipidol 14:249-254

38. Kayden HJ, Traber MG (1993) Absorption, lipoprotein transport and regulation of plasma concentrations of vitamin $\mathrm{E}$ in humans. J Lipid Res 34:343-358

39. Khanna S, Patel V, Rink C, Roy S, Sen CK (2005) Delivery of orally supplemented $\alpha$-tocotrienol to vital organs of rats and tocopherol-transfer protein deficient mice. Free Rad Biol Med 39:1310-1319

40. Khosla P, Patel V, Whinter JM, Khanna S, Rakhkovskaya M, Roy S, Sen C (2006) Postprandial levels of the natural vitamin E tocotrienol in human circulation. Antioxid Redox Signal 8:1059-1068

41. Lonn E, Bosch J, Yusuf S, Sheridan P, Pogue J, Arnold JMO, Ross C, Sleight P, Probstfield J, Dagenais GR, Hope And Hope Too Trial Investigators (2005) Effects of long-term vitamin E supplementation on cardiovascular events and cancer: a randomized controlled trial. JAMA 293:1338-1347

42. Manuel-y-Keenoy B, Vinckx M, Vertommen J, van Gaal L, de Leeuw I (2004) Impact of vitamin E supplementation on lipoprotein peroxidation and composition in type 1 diabetic patients treated with atorvastatin (DATOR). Atherosclerosis 175:369-376

43. Marras C, Mcdermott MP, Rochon PA, Tanner CM, Naglie G, Rudolph A, Lang AE, Parkinson Study Group (2005) Survival in Parkinson disease: thirteen-year follow-up of the DATATOP cohort. Neurology 64:87-93

44. Matsumoto A, Takahashi S, Nakano K, Kijima S (1995) Identification of new vitamin $\mathrm{E}$ in plant oil. J Jpn Oil Chem Soc 44:593-597

45. de la Maza MP, Petermann M, Bunout D, Hirsch S (1995) Effects of long-term vitamin $\mathrm{E}$ supplementation in alcoholic cirrhotics. J Am Coll Nutr 14:192-196

46. McIntyre BS, Briski KP, Gapor A, Sylvester PW (2000) Antiproliferative and apoptotic effects of tocopherols and tocotrienols on preneoplastic and neoplastic mouse mammary epithelial cells. Proc Soc Exp Biol Med 224:292-301

47. McNeil JJ, Robman L, Tikellis G, Sinclair MI, Mccarty CA, Taylor HR (2004) Vitamin E supplementation and cataract (VECAT): randomized controlled trial. Ophthalmology 111:75-84

48. Mezey E, Potter JJ, Rennie-Tankersley L, Caballeria J, Pares A (2004) A randomized placebo controlled trial of vitamin $E$ for alcoholic hepatitis. J Hepatol 40:40-46

49. Meier R, Tomizaki T, Schulze-Briese C, Baumann U, Stocker A (2003) The molecular basis of vitamin E retention: structure of human $\alpha$-tocopherol transfer protein. J Mol Biol 331:725-734

50. Miller ER III, Pastor-Barriuso R, Dalal D, Riemerma RA, Appel LJ, Guallar E (2005) Meta-analysis: high-dosage vitamin E supplementation may increase all-cause mortality. Ann Int Med 142:37-46

51. Min CK, Kovall RA, Hendrikson WA (2003) Crystal structure of human $\alpha$-tocopherol transfer protein bound to its ligand: implications for ataxia with vitamin E deficiency. Proc Natl Acad Sci USA 100:14713-14718

52. Minehira-Castelli K, Leonard SW, Walker QM, Traber MG, Young SG (2006) Absence of VLDL secretion does not affect $\alpha$-tocopherol content in peripheral tissues. J Lipid Res 47:1733-1738

53. Miyazawa T, Shibata T, Sookwong P, Kawakami Y, Eitsuka T, Asai A, Oikawa S, Nakagawa K (2009) Antiangiogenic and anticancer potential of unsaturated vitamin E (tocotrienol). J Nutr Biochem 20:79-86

54. Mizushima Y, Nakagawa K, Shibata A, Awata Y, Kuriyama I, Shimazaki N, Koiwai O, Uchiyama Y, Sakaguchi K, Miyazawa 
T, Yoshida H (2006) Inhibitory effect of tocotrienol on eukaryotic DNA polymerase $\lambda$ and angiogenesis. Biochem Biophys Res Comm 339:949-955

55. Naito $Y$, Shimozama M, Kuroda M, Nakabe N, Manabe H, Katada K, Kokura S, Ichikawa H, Yoshida N, Naguchi N, Yoshikawa T (2005) Tocotrienols reduce 25-hydroxycholesterolinduced monocyte-endothelial cell interaction by inhibiting the surface expression of adhesion molecules. Atherosclerosis 180:19-25

56. Nakagawa K, Shibata A, Yamashita S, Tsuzuki T, Kariya J, Oikawa S, Miyazawa T (2007) In vivo angiogenesis is suppressed by unsaturated vitamin E, tocotrienol. J Nutr 137:1938-1943

57. Nesaretnam K, Gomez PA, Selvaduray KR, Razak GA (2007) Tocotrienol levels in adipose tissue of benign and malignant breast lumps in patients in Malaysia. Asia Pac J Clin Nutr 16:498-504

58. Ouahchi K, Arita M, Kayden H, Hentati F, Hamida MB, Sokol R, Arai H, Inoue K, Mandel J-L, Koenig M (1995) Ataxia with isolated vitamin $\mathrm{E}$ deficiency is caused by mutations in the $\alpha$-tocopherol transfer protein. Nat Genet 9:141-145

59. Panfili G, Fratianni A, Irano M (2003) Normal phase high-performance liquid chromatography method for the determination of tocopherols and tocotrienols in cereals. J Agric Food Chem 51:3940-3944

60. Park SK, Saunders BG, Kline K (2010) Tocotrienols induce apoptosis in breast cancer cell lines via an endoplasmic reticulum stress-dependent increase in extrinsic death receptor signaling. Breast Cancer Res Treat doi: 10.1007/s10549-010-0786-2

61. Peralta EA, Viegas ML, Louis S, Engle DL, Dunnington GL (2006) Effect of vitamin E on tamoxifen-treated breast cancer cells. Surgery 140:607-615

62. Peralta EA, Brewer AT, Louis S, Engle DL, Dunnington GL (2009) Vitamin E increases biomarkers of estrogen stimulation when taken with tamoxifen. J Surg Res 153:143-147

63. Petersen RC, Thomas RG, Grundman M, Bennett D, Doody R, Ferris S, Galasko D, Jin S, Kaye J, Levey A, Pfeiffer E, Sano M, van Dyck CH, Thal LJ (2005) Alzheimer's Disease Cooperative Study (ADCS2) Group. Vitamin E and donepezil for the treatment of mild cognitive impairment. $N$ Engl J Med 352:2379-2388

64. Qureshi AA, Pearce BC, Nor RM, Gapor A, Petersen DM, Elson CE (1996) Dietary $\alpha$-tocopherol attenuates the impact of $\gamma$-tocotrienol on hepatic 3-hydroxy-3-methylglutaryl co-enzyme A reductase activity in chickens. J Nutr 126:389-394

65. Reboul E, Klein A, Bietrix F, Gleize B, Malezet-Desmoulins C, Schneider M, Margotat A, Lagrost L, Collet X, Borel P (2006) Scavenger receptor class B type I (SR-BI) is involved in vitamin E transport across the enterocyte. J Biol Chem 281:4739-4745

66. Rigotti A (2007) Absorption, transport and tissue delivering of vitamin E. Mol Aspects Med 28:423-436

67. Ryynänen M, Lampi A-M, Salo-Väänänen P, Ollilainen V, Piironen V (2004) A small-scale sample preparation method with HPLC analysis for determination of tocopherols and tocotrienols in cereals. J Food Compos Anal 17:749-765

68. Salonen RM, Nyyssonen K, Kaikkonen J, Porkkala-Sarataho E, Voutilainen S, Rissanen TH, Tuomainen T-P, Valkonen V-P, Ristonmaa U, Lakka H-M, Vanharanta M, Salonen JT, Poulsen HE (2003) Antioxidant supplementation in atherosclerosis prevention study (ASAP): six-year effect of combined vitamin C and E supplementation on atherosclerotic progression: the Antioxidant Supplementation in Atherosclerosis Prevention (ASAP) Study. Circulation 107:947-953

69. Sano M, Ernesto C, Thomas RG, Klauber MR, Schafer K, Grundman M, Woodbury P, Growdon J, Cotman CW, Pfeiffer E, Schneider LS, Thal LJ (1997) A controlled trial of selegiline, alpha-tocopherol, or both as treatment for Alzheimer's disease: the Alzheimer's Disease Cooperative Study (ADCS1). N Engl J Med 336:1216-1222

70. Scientific opinion of the panel on food additives, flavourings, processing aids and materials in contact with food on a request from the commission on mixed tocopherols, tocotrienol tocopherol and tocotrienols as sources for vitamin E (2008) EFSA J 640: $1-34$

71. Sen CK, Khanna S, Roy S, Packer L (2000) Molecular basis of vitamin E action. J Biol Chem 275:13047-13055

72. Sen CK, Khanna S, Roy S (2007) Tocotrienols in health and disease: the other half of the natural vitamin E family. Mol Aspects of Med 28:693-728

73. Schonfeld G, Bell E, Alpers DH (1978) Intestinal apoproteins during fat absorption. J Clin Invest 61:1539-1550

74. Shirode AB, Sylvester PW (2009) Synergistic anticancer effects of combined $\gamma$-tocotrienol and celecoxib treatment are associated with suppressing in Akt and $\mathrm{NF} \kappa \mathrm{B}$ signaling. Biomedic Pharmacother (in press) doi: 10.1016/j.biopha.2009.09.018

75. Stalenhoef AFH, Malloy MJ, Kane JP, Havel RJ (1984) Metabolism of apolipoproteins B-48 and B-100 of triglyceride-rich lipoproteins in normal and lipoprotein lipase-deficient humans. Proc Natl Acad Sci USA 81:1839-1843

76. Stephens NG, Parsons A, Schofield PM, Kelly F, Cheeseman K, Mitchinson MJ (1996) Randomised controlled trial of vitamin E in patients with coronary disease: Cambridge Heart Antioxidant Study (CHAOS). Lancet 347:781-786

77. Takagi H, Kakizaki S, Sohara N, Sato K, Tsukioka G, Tago Y, Konaka K, Kabeya K, Kaneko M, Takayama H, Hashimoto Y, Yamada T, Takahashi H, Shimojo H, Nagamine T, Mori M (2003) Pilot clinical trial of the use of alpha-tocopherol for the prevention of hepatocellular carcinoma in patients with liver cirrhosis. Int J Vit Nutr Res 73:411-415

78. Takamatsu S, Takamatsu M, Satoh K, Imaizumi T, Yoshida H, Hiramoto M, Koyama M, Ohgushi Y, Mizuno S (1995) Effects on health of dietary supplementation with $100 \mathrm{mg} d$-alphatocopheryl acetate, daily for 6 years. J Int Med Res 23:342-357

79. Thiele JJ, Traber MG, Packer L (1998) Depletion of human stratum corneum vitamin E: an early and sensitive in vivo marker of UV induced photo-oxidation. J Invest Dermatol 110:756-761

80. Thiele JJ, Weber SU, Packer L (1999) Sebaceous gland secretion is a major physiologic route of vitamin E delivery to skin. J Invest Dermatol 113:1006-1010

81. Traber MG, Kayden HJ (1989) Preferential incorporation of $\alpha$-tocopherol vs. $\gamma$-tocopherol in human lipoproteins. Am J Clin Nutr 49:517-526

82. Traber MG, Burton GW, Ingold KU, Kayden HJ (1990) RRR- and $S R R-\alpha$-Tocopherols are secreted without discrimination in human chylomicrons, but $R R R$ - $\alpha$-tocopherol is preferentially secreted in very low density lipoproteins. J Lipid Res 31:675-685

83. Traber MG, Lane JC, Lagmay NR, Kayden HJ (1992) Studies on the transfer of tocopherol between lipoproteins. Lipids 27:657-663

84. Traber MG (1996) Biokinetics of vitamin E. In: Cadenas E, Packer L (eds) Handbook of antioxidants. Marcel Dekker Inc., New York, pp 43-61

85. Traber MG (2004) The ABCs of vitamin E and beta-carotene absorption. Am J Clin Nutr 80:3-4

86. Virtamo J, Pietinen P, Huttunen JK, Korhonen P, Malila N, Virtanen MJ, Albanes D, Taylor PR, Albert P, ATBC Study Group (2003) Incidence of cancer and mortality following alphatocopherol and beta-carotene (ATBC) supplementation: a postintervention follow-up. JAMA 290:476-485

87. de Waart FG, Kok FJ, Smilde TJ, Hijmans A, Wollersheim H, Stalenhoef AF (2001) Effect of glutathione $S$-transferase M1 genotype on progression of atherosclerosis in lifelong male smokers. Atherosclerosis 158:227-231 
88. Wali VB, Sylvester PW (2007) Synergistic antiproliferative effects of $\gamma$-tocotrienol and statin treatment on mammary tumor cells. Lipids 42:1113-1123

89. Wali VB, Bachawal SV, Sylvester PW (2009) Suppression in mevalonate synthesis mediates antitumor effects of combined statin and $\gamma$-tocotrienols treatment. Lipids 44:925-934

90. Whatson RR, Preedy VR (eds) (2008) Tocotrienols: vitamin E beyond tocopherols. AOCS Press, Urbana

91. Wluka AE, Stuckey S, Brand C, Cicuttini FM (2002) Supplementary vitamin $\mathrm{E}$ does not affect the loss of cartilage volume in knee osteoarthritis: a 2 year double blind randomized placebo controlled study. J Rheumatol 29:2585-2591

92. Wu JH, Croft KD (2007) Review: vitamin E metabolism. Mol Aspects Med 2007(28):437-452
93. Yamamoto Y, Fujisawa A, Hara A, Dunlap WC (2001) An unusual vitamin $\mathrm{E}$ constituent ( $\alpha$-tocomonoenol) provides enhanced antioxidant protection in marine organisms adapted to cold-water environments. Proc Natl Acad Sci USA 23:13144-13148

94. Yap SP, Yuen KH, Wong JW (2001) Pharmacokinetics and bioavailability of $\alpha$-, $\gamma$ - and $\delta$-tocotrienol under different food status. J Pharm Pharmacol 53:67-71

95. Yap WN, Chang PN, Han HY, Lee DTW, Ling MT, Wong YC, Yap YL (2008) $\gamma$-Tocotrienol suppresses prostate cancer cell proliferation and invasion through multiple-signalling pathways. Br J Cancer 99:1-10

96. Young SG (1990) Recent progress in understanding apolipoprotein B. Circulation 82:1574-1594 